\title{
Prevalence of comorbid chronic pain and mental health conditions in Canadian Armed Forces active personnel: analysis of a cross-sectional survey
}

\author{
Everett Vun BSc, Sarah Turner MSc, Jitender Sareen MD, Natalie Mota PhD, Tracie O. Afifi PhD, \\ Renée El-Gabalawy PhD
}

\section{Abstract}

Background: Chronic pain conditions and mental disorders have high prevalence rates in military populations. However, few investigations have examined the comorbidity between chronic pain conditions and specific mental disorders among Canadian active military personnel.

Methods: We conducted a secondary analysis of data from the 2013 Canadian Forces Mental Health Survey (CFMHS) concerning the population of regular members. Diagnostic interviews assessed the presence of mental disorders, and participants self-reported chronic pain conditions (i.e., arthritis, back problems, musculoskeletal conditions, migraines) and indicators of pain severity. We used multiple logistic regressions to assess associations between chronic pain conditions and mental disorders. We used cross-tabulations to assess the prevalence of pain severity indicators in comorbid relationships compared with the chronic pain condition alone. We used moderation analyses to examine the interactions between pain condition by pain severity, and pain condition by activity limitation, respectively, on mental disorders.

Results: The CFMHS included data from 6696 regular members and had a response rate of $79.8 \%$. About one-quarter $(n=1761)$ of military personnel reported having chronic pain. In the fully adjusted model, all assessed pain conditions were significantly associated with posttraumatic stress disorder (PTSD) (odds ratio [OR] range 1.86-2.55), and several pain conditions were associated with major depressive episode, generalized anxiety disorder and panic disorder. Back problems were significantly associated with all mental disorders apart from alcohol use disorders (OR range 1.40-2.17). Cross-tabulations showed higher prevalence estimates of endorsement for pain severity indicators among pain conditions and comorbid mental disorders, compared with pain conditions alone. Formal moderation analyses showed a significant relationship between migraine and activity limitation on PTSD.

Interpretation: Chronic pain conditions are prevalent and co-occur with mental disorders among Canadian regular force members. Greater understanding of these chronic pain conditions and mental disorders and their impact on people's abilities to adapt to both military and civilian life is needed.

hronic pain, physical conditions and mental disorders are prevalent among military personnel. Chronic pain estimates in former members of the Canadian Armed Forces (CAF) are estimated to be about $41 \% .{ }^{1}$ Although some research has shown higher chronic pain estimates in the Canadian veteran population compared with the general population, ${ }^{2}$ other studies have shown comparable prevalence estimates among the two populations. ${ }^{3}$ In addition, there are no recent estimates of the prevalence of chronic pain in the serving CAF.

Canadian regular force veterans have higher rates of conditions characterized by pain, including arthritis, back pain and bowel disorders compared with the general population. ${ }^{4}$ High estimates of mental health conditions are also seen. In 2002, the Canadian Community Health Survey Canadian Forces
Supplement (CCHS-CF) showed significantly higher pastyear prevalence rates of depression and panic disorder among regular members of the CAF compared with the rates seen in the general population. ${ }^{5}$ High prevalence rates in the CAF are corroborated by more recent research, with the prevalence of general anxiety disorder being twice as high as that of the general population in $2008 .^{4}$

Competing interests: None declared.

This article has been peer reviewed.

Correspondence to: Renée El-Gabalawy, renee.el-gabalawy@ umanitoba.ca

CMAJ Open 2018. DOI:10.9778/cmajo.20180093 
Interest in the relationship between mental disorders and pain conditions is growing. General population-based studies have found strong relations between chronic physical pain conditions and depression, ${ }^{6-10}$ anxiety disorders ${ }^{1-13}$ and posttraumatic stress disorder (PTSD) ${ }^{14-16}$ among other mental disorders. ${ }^{17}$ Comorbid physical and mental conditions are associated with greater disability and activity limitation compared with a single condition alone, ${ }^{18-20}$ which suggests that the presence of physical pain may moderate these associations. Further, research has shown a significant association between chronic pain and certain mental disorders. ${ }^{20}$ However, a limitation of these studies is the lack of research looking at specific mental disorders; research examining comorbid relationships has primarily examined summary disorder categories. Lack of research examining chronic pain severity as a potential mechanism or differentiating factor for these comorbid relations is an additional limitation. Assessing pain severity would provide a better understanding of the role mental disorders have on the prevalence of pain severity and activity limitations among people with pain conditions. There are even greater gaps within the military context regarding comorbidity research. Research involving the military population has primarily focused on PTSD and its relationship with physical conditions. ${ }^{14,15,21}$ Furthermore, there is limited research within the Canadian military context regarding these comorbidities, particularly among active duty personnel. Here, we address many of these limitations by investigating the relations between specific mental disorders, chronic pain severity and pain conditions in a contemporary sample population of active military personnel in Canada.

Our objectives were to estimate the prevalence of chronic pain and physical conditions characterized by pain among Canadian military personnel, examine the association between pain conditions and mental disorders and assess severity indicators of chronic pain between comorbid pain conditions and mental disorders.

\section{Methods}

\section{Data source and study population}

We conducted a secondary analysis of data drawn from the cross-sectional 2013 Canadian Forces Mental Health Survey (CFMHS) conducted by Statistics Canada. The CFMHS sample population was a nationally representative sample of regular force members and a nonrepresentative sample of reserve force members. ${ }^{22}$ For this reason, we included only regular force members in our study. Statistics Canada stratified the sample by deployment status and rank to ensure representativeness of the regular force members. ${ }^{22}$

Interviewers surveyed respondents face-to-face using a computer-assisted interviewing technique. Survey questions were based partly on the World Mental Health Survey, the Canadian Community Health Survey (CCHS; cycle 5.2) and other special surveys. ${ }^{22}$ Qualitative testing of the questionnaire was conducted in 2011 to evaluate respondents' understanding of the survey and assess their willingness and ability to provide information. ${ }^{22}$ Statistics Canada used a complex sampling design to ensure representativeness. Consent was given by respondents before the start of the survey. Data were collected between Apr. 15 and Aug. 31, 2013.22

\section{Primary variables}

\section{Mental disorders}

The World Health Organization version of the Composite International Diagnostic Interview (WHO-CIDI ${ }^{23}$ based on Diagnostic and Statistical Manual of Mental Disorders-IV (DSM-IV) ${ }^{24}$ and the 10th revision of the International Statistical Classification of Diseases and Related Health Problems (ICD-10) criteria assessed past-year mental disorders. Codes for major depressive episode (MDE), GAD, panic disorder, PTSD and alcohol use disorder (AUD) were included in the analysis. ${ }^{23}$ Research has shown concordance between the WHO-CIDI and Structured Clinical Interviews for DSM-IV (SCID). ${ }^{25}$

\section{Pain conditions}

Physical conditions in this study included those that were frequently characterized by pain, were expected to last or had already lasted at least 6 months and were based on selfreport of having been diagnosed by a health professional. Pain conditions included arthritis; back problems excluding fibromyalgia and arthritis; other musculoskeletal problems and fibromyalgia; and migraine headaches. An "any pain condition" variable was computed for any respondents who reported 1 or more pain conditions. Physical conditions such as asthma and diabetes — included within the CFMHS - were not included within this study because they are not primarily characterized by pain, and because they have low prevalence rates within this young adult population. Gastrointestinal diseases were not assessed in the CFMHS.

\section{Chronic pain characteristics}

Among all respondents, the presence of chronic pain was assessed using the question "Are you usually free of pain or discomfort," with self-reported "no" answers suggesting chronic pain. Pain was further characterized by severity and the number of activities prevented. Pain severity was assessed by a description of the usual intensity of their pain or discomfort: "mild," "moderate" or "severe." The respondent was able to select from 4 options (none, a few, some, most) to describe the number of activities prevented owing to pain or discomfort. This style of question regarding activity limitation has been used in several iterations of the CCHS and has been used to assess the prevalence of chronic pain within the general population. ${ }^{3}$ We created the following categorizations based on prevalent responses and sensitivity analyses: "no pain and mild pain" or "moderate and severe pain" for pain severity, and "no pain, none or a few" activities prevented or "some to most" activities prevented. 


\section{Sociodemographic and military variables}

Sociodemographic variables included age (assessed continuously), sex, marital status (married or common-law; separated, divorced or widowed; single, never married), education level (high school or less; some postsecondary; trade, college, or university certificate or diploma; university degree), household income ( $\leq \$ 29$ 999; \$30 000-\$49 999; \$50 000-\$79 999; $\geq \$ 80000$ ) and ethnicity (white, other). Military-related variables include rank (junior noncommissioned member, senior noncommissioned member, officer) and CAF element (army, navy, air force). Marital status and income were categorized in accordance with other literature that has used the CFMHS; ${ }^{26}$ education level, ethnicity and military rank were derived variables created by Statistics Canada.

\section{Analytical strategy}

We used cross-tabulations to derive frequencies for the presence of chronic pain among each physical condition and the presence of individual mental disorders (i.e., major depressive episode, generalized anxiety disorder, panic disorder, PTSD, AUD) among each pain condition. We used bivariate (model 1) and multiple logistic regression models to assess the relation between pain conditions (independent variable) and each mental disorder (dependent variable). We adjusted multivariable models for sociodemographic factors (age, sex, marital status, education level, income, ethnicity, rank, CAF element) (model 2), and for sociodemographic factors and mental disorders (excluding the disorder of interest) (model 3).

To examine the effect of pain severity in comorbid relations, we used cross-tabulations to examine the proportion of respondents who reported severe versus mild pain severity and activity limitation, with and without the mental disorder of interest, for each pain condition. This was done only among the pain conditions that were significantly associated with mental disorders in the fully adjusted logistic regression model. We then conducted a moderation analysis by entering the main effects and interaction terms into the same model to test the significance of the relations between pain condition by pain severity and pain condition by activity limitation with each mental disorder. To ensure representativeness of the CAF regular force, we weighted analyses using final probability weights derived from Statistics Canada and adjusted for nonresponse and the exclusion of out-of-scope units. ${ }^{27} \mathrm{We}$ applied bootstrapping for variance estimation to account for the complex survey design using 500 replicate weights supplied by Statistics Canada. We conducted all analyses in STATA software. ${ }^{28}$

\section{Ethics approval}

Ethical approval to conduct the survey was obtained through the relevant bodies within Statistics Canada. ${ }^{27}$

\section{Results}

\section{Sample description}

The CFMHS included data from 6696 regular members of the CAF, and had a response rate of $79.8 \% .{ }^{25}$ Table 1 includes a description of the sample. The mean age of included respondents was 35 years, and most respondents were male $(86.1 \%, n=5773)$. The army was the most prevalent CAF element in the sample $(53.1 \%, n=3459)$, and junior noncommissioned member was the most prevalent rank $(55.0 \%, n=2816)$. About one-quarter of the respondents indicated chronic pain or discomfort $(25.5 \%, n=1761)$; of these respondents, more than $60 \%(n=1102)$ deemed their pain to be moderate to severe. "Other musculoskeletal problems and fibromyalgia" was the most prevalent pain condition $(30.5 \%, n=2130)$, and $46.7 \%(n=3243)$ of respondents had any pain condition.

Cross-tabulations to examine the presence of chronic pain among each condition showed that, of respondents with arthritis, $70.1 \%$ (weighted $n=5380$ out of 7680 with arthritis) reported chronic pain, followed by back problems $(57.8 \%$, weighted $n=8660$ out of 14980), other musculoskeletal problems and fibromyalgia (51.5\%, weighted $n=10100$ out of 19600 ) and migraine ( $47.3 \%$, weighted $n=2780$ out of 5880 ) (data not shown).

\section{Comorbidities}

Table 2 shows the prevalence of mental disorders among each pain condition. All pain conditions were significantly associated with major depressive episode, generalized anxiety disorder and panic disorder in both model 1 and model 2. Once adjusted for other mental disorders, only PTSD remained significantly associated with all pain conditions (model 3 odds ratio [OR] range 1.86-2.55); however, major depressive episode, generalized anxiety disorder and panic disorder remained significantly associated with some pain conditions. No significant relations were seen between alcohol use disorder and pain conditions in the fully adjusted model.

\section{Pain severity analyses}

Cross-tabulations calculated on the significant regression results of the fully adjusted model showed that, among the pain conditions, a larger proportion of respondents endorsed severe pain when the mental disorder of interest was present, compared with when it was not (Table 3). Similar results were seen with regard to activity limitation, with the presence of a mental disorder yielding higher proportions of greater activity limitations compared with those with the pain condition alone. When conducting formal interaction analyses, a significant relation was seen only between migraine and activity limitation on PTSD $(p<0.05)$ (Figure 1). No other interaction analyses between physical conditions, mental disorders and activity limitation reached significance.

\section{Interpretation}

In our investigation that examined mental and physical health comorbidities and the effect of chronic pain among the active regular force members of the CAF, $25 \%$ of the included respondents reported regular chronic pain. The strength of 
Table 1: Characteristics of included respondents

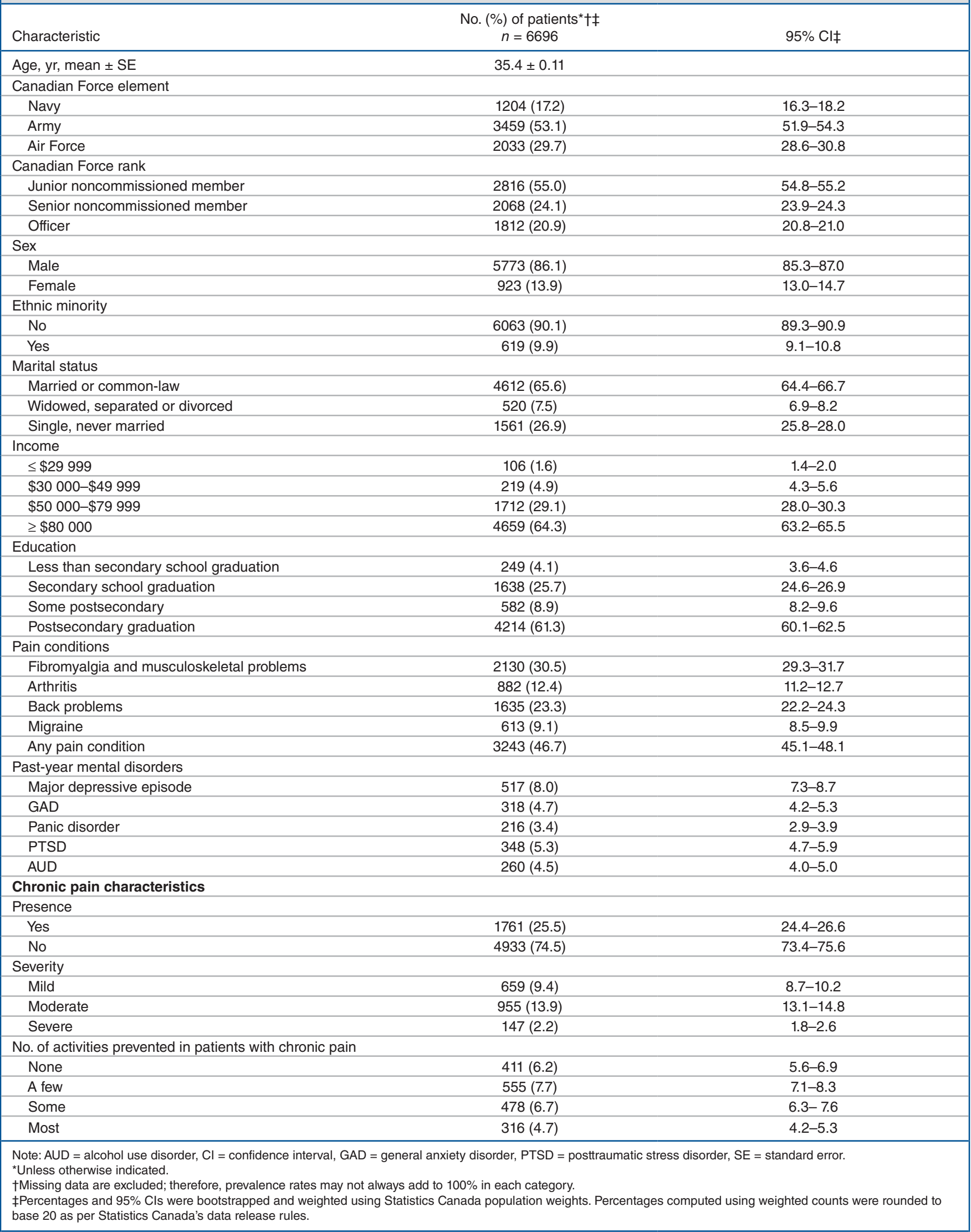




\begin{tabular}{|c|c|c|c|c|c|c|c|c|c|c|}
\hline \multirow{3}{*}{$\begin{array}{l}\text { Physical } \\
\text { conditions }\end{array}$} & \multicolumn{10}{|c|}{ Mental disorders, \% (95\% Cl) } \\
\hline & \multicolumn{2}{|c|}{ MDE } & \multicolumn{2}{|c|}{ GAD } & \multicolumn{2}{|c|}{ Panic disorder } & \multicolumn{2}{|c|}{ PTSD } & \multicolumn{2}{|c|}{ AUD } \\
\hline & Yes & No & Yes & No & Yes & No & Yes & No & Yes & No \\
\hline Musculoskeletal & $n=247$ & $n=270$ & $n=147$ & $n=171$ & $n=114$ & $n=104$ & $n=187$ & $n=161$ & $n=81$ & $n=179$ \\
\hline & $\begin{array}{c}12.2 \\
(10.7-13.9)\end{array}$ & $\begin{array}{c}6.1 \\
(5.4-6.9)\end{array}$ & $\begin{array}{c}6.9 \\
(5.9-8.2)\end{array}$ & $\begin{array}{c}3.7 \\
(3.2-4.4)\end{array}$ & $\begin{array}{c}5.7 \\
(4.7-6.9) \\
\end{array}$ & $\begin{array}{c}2.4 \\
(1.9-2.9)\end{array}$ & $\begin{array}{c}9.0 \\
(7.8-10.5)\end{array}$ & $\begin{array}{c}3.6 \\
(3.0-4.3)\end{array}$ & $\begin{array}{c}4.5 \\
(3.5-5.6)\end{array}$ & $\begin{array}{c}4.5 \\
(3.9-5.2)\end{array}$ \\
\hline \multicolumn{11}{|c|}{ Odds ratios $(95 \% \mathrm{Cl})$} \\
\hline Model 1 & \multicolumn{2}{|c|}{$2.13(1.74-2.61)^{\star}$} & \multicolumn{2}{|c|}{$1.92(1.50-2.49)^{*}$} & \multicolumn{2}{|c|}{$2.52(1.87-3.39)^{*}$} & \multicolumn{2}{|c|}{$2.68(2.11-3.40)^{*}$} & \multicolumn{2}{|c|}{$0.99(0.73-1.34)$} \\
\hline Model 2 & \multicolumn{2}{|c|}{$2.12(1.73-2.61)^{*}$} & \multicolumn{2}{|c|}{$1.78(1.37-2.32)^{*}$} & \multicolumn{2}{|c|}{$2.37(1.75-3.21)^{\star}$} & \multicolumn{2}{|c|}{$2.47(1.92-3.17)^{\star}$} & \multicolumn{2}{|c|}{$1.36(0.99-1.86)$} \\
\hline Model 3 & \multicolumn{2}{|c|}{$1.80(1.42-2.29)^{*}$} & \multicolumn{2}{|c|}{$1.04(0.74-1.45)$} & \multicolumn{2}{|c|}{$1.75(1.23-2.49) \dagger$} & \multicolumn{2}{|c|}{$1.88(1.42-2.50)^{*}$} & \multicolumn{2}{|c|}{$1.04(0.73-1.48)$} \\
\hline & & & & & $95 \% \mathrm{Cl})$ & & & & & \\
\hline Arthritis & Yes & No & Yes & No & Yes & No & Yes & No & Yes & No \\
\hline & $n=97$ & $n=419$ & $n=72$ & $n=246$ & $n=57$ & $n=159$ & $n=88$ & $n=260$ & $n=27$ & $n=233$ \\
\hline & $\begin{array}{c}11.5 \\
(9.4-14.0)\end{array}$ & $\begin{array}{c}7.5 \\
(6.8-8.2)\end{array}$ & $\begin{array}{c}8.2 \\
(6.6-10.4)\end{array}$ & $\begin{array}{c}4.2 \\
(3.7-4.8)\end{array}$ & $\begin{array}{c}7.5 \\
(5.7-9.6)\end{array}$ & $\begin{array}{c}2.8 \\
(2.4-3.4)\end{array}$ & $\begin{array}{c}10.4 \\
(8.3-13.1)\end{array}$ & $\begin{array}{c}4.6 \\
(4.0-5.2)\end{array}$ & $\begin{array}{c}3.7 \\
(2.5-5.3)\end{array}$ & $\begin{array}{c}4.6 \\
(4.1-5.2)\end{array}$ \\
\hline & & & & Odds $\mathrm{r}$ & ios $(95 \% \mathrm{Cl}$ & & & & & \\
\hline Model 1 & $1.61(1.24$ & $4-2.08)^{*}$ & $2.05(1$. & $3-2.74)^{\star}$ & $2.73(1$. & $5-3.81)^{*}$ & $2.44(1 . \varepsilon$ & $4-3.24)^{*}$ & $0.78(0$ & 52-1.18) \\
\hline Model 2 & $1.51(1.14$ & $1-2.00) \dagger$ & $1.73(1.2$ & S-2.37)† & 2.41 & $0-3.41)^{*}$ & 2.09 & $3-2.86)^{*}$ & $1.50(0$. & $4-2.40)$ \\
\hline Model 3 & $1.10(0.7$ & 76-1.60) & $1.23(0$ & $1-1.85)$ & 1.80 & $-2.82) \ddagger$ & $1.86(1.2$ & $9-2.70) \dagger$ & $1.26(0$. & $5-2.14)$ \\
\hline & & & & & $95 \% \mathrm{Cl})$ & & & & & \\
\hline Back problems & Yes & No & Yes & No & Yes & No & Yes & No & Yes & No \\
\hline & $n=207$ & $n=310$ & $n=149$ & $n=168$ & $n=106$ & $n=109$ & $n=174$ & $n=174$ & $n=67$ & $n=193$ \\
\hline & $\begin{array}{c}13.2 \\
(11.5-15.2)\end{array}$ & $\begin{array}{c}6.4 \\
(5.7-7.1)\end{array}$ & $\begin{array}{c}9.6 \\
(8.2-11.3)\end{array}$ & $\begin{array}{c}3.2 \\
(2.7-3.8)\end{array}$ & $\begin{array}{c}7.4 \\
(6.1-9.1)\end{array}$ & $\begin{array}{c}2.1 \\
(1.8-2.6)\end{array}$ & $\begin{array}{c}11.2 \\
(9.5-13.0)\end{array}$ & $\begin{array}{c}3.5 \\
(3.0-4.1)\end{array}$ & $\begin{array}{c}4.4 \\
(3.4-5.7)\end{array}$ & $\begin{array}{c}4.5 \\
(3.9-5.2)\end{array}$ \\
\hline & & & & Odds $\mathrm{r}$ & $\operatorname{ios}(95 \% \mathrm{Cl}$ & & & & & \\
\hline Model 1 & $2.26(1.8$ & $5-2.75)^{*}$ & $3.21(2$. & $2-4.09)^{\star}$ & 3.65 & $2-4.90)^{*}$ & $3.46(2$. & $5-4.36)^{*}$ & $0.96(0$ & (0-1.33) \\
\hline Model 2 & $2.21(1.7$ & $9-2.74)^{*}$ & 2.97 & $9-3.85)^{*}$ & 3.41 & $2-4.62)^{*}$ & $3.11(2$. & $4-3.97)^{*}$ & $1.41(1.0$ & $0-1.97) \ddagger$ \\
\hline Model 3 & $1.40(1.0$ & $5-1.87) \ddagger$ & $1.78(1.2$ & $9-2.47)^{\star}$ & $1.90(1.2$ & $3-2.92) \dagger$ & $2.17(1.6$ & $1-2.93)^{\star}$ & $0.99(0$ & (7-1.45) \\
\hline & & & & & $95 \% \mathrm{Cl})$ & & & & & \\
\hline Migraines & Yes & No & Yes & No & Yes & No & Yes & No & Yes & No \\
\hline & $n=107$ & $n=409$ & $n=55$ & $n=263$ & $n=49$ & $n=165$ & $n=86$ & $n=261$ & $n=28$ & $n=232$ \\
\hline & $\begin{array}{c}17.4 \\
(14.4-20.9)\end{array}$ & $\begin{array}{c}7.0 \\
(6.3-7.7)\end{array}$ & $\begin{array}{c}8.9 \\
(6.8-11.5)\end{array}$ & $\begin{array}{c}4.3 \\
(3.8-4.9)\end{array}$ & $\begin{array}{c}8.0 \\
(5.9-10.3)\end{array}$ & $\begin{array}{c}2.9 \\
(2.5-3.4)\end{array}$ & $\begin{array}{c}14.5 \\
(11.8-18.0)\end{array}$ & $\begin{array}{c}4.3 \\
(3.8-4.9)\end{array}$ & $\begin{array}{c}5.8 \\
(3.9-8.5)\end{array}$ & $\begin{array}{c}4.4 \\
(3.8-5.0)\end{array}$ \\
\hline & & & & Odds $\mathrm{r}$ & ios $(95 \% \mathrm{Cl}$ & & & & & \\
\hline Model 1 & $2.80(2.1$ & $6-3.62)^{*}$ & 2.18 & $7-3.02)^{\star}$ & 2.85 & $8-4.09)^{*}$ & $3.80(2.8$ & $5-5.07)^{\star}$ & $1.35(0$. & $7-2.08)$ \\
\hline Model 2 & $2.62(2.0$ & $0-3.44)^{*}$ & 1.92 & $8-2.66)^{*}$ & 2.49 & $1-3.64)^{*}$ & 3.30 & $1-4.50)^{\star}$ & $1.66(1.0$ & 7-2.57)‡ \\
\hline Model 3 & 2.02 & $3-2.86)^{\star}$ & $0.95(0$ & (0-1.48) & $1.53(0$. & 7-2.42) & 2.55 & $5-3.72)^{\star}$ & $1.17(0$. & $1-1.94)$ \\
\hline & & & & & $95 \% \mathrm{Cl})$ & & & & & \\
\hline & Yes & No & Yes & No & Yes & No & Yes & No & Yes & No \\
\hline $\begin{array}{l}\text { Any pain } \\
\text { condition }\end{array}$ & $n=351$ & $n=166$ & $n=220$ & $n=98$ & $n=164$ & $n=52$ & $n=269$ & $n=79$ & $n=125$ & $n=135$ \\
\hline & $\begin{array}{c}11.3 \\
(10.2-12.6)\end{array}$ & $\begin{array}{c}5.0 \\
(4.3-5.8)\end{array}$ & $\begin{array}{c}6.9 \\
(6.1-7.9)\end{array}$ & $\begin{array}{c}2.8 \\
(2.3-3.4)\end{array}$ & $\begin{array}{c}5.4 \\
(4.6-6.4)\end{array}$ & $\begin{array}{c}1.6 \\
(1.2-2.1)\end{array}$ & $\begin{array}{c}8.7 \\
(7.7-9.9)\end{array}$ & $\begin{array}{c}2.2 \\
(1.8-2.8)\end{array}$ & $\begin{array}{c}4.6 \\
(3.8-5.5)\end{array}$ & $\begin{array}{c}4.4 \\
(3.7-5.3)\end{array}$ \\
\hline & & & & Odds $r$ & ios $(95 \% \mathrm{Cl}$ & & & & & \\
\hline Model 1 & $2.42(1.9$ & $6-2.99)^{*}$ & 2.59 & $1-3.33)^{\star}$ & 3.63 & $3-5.19)^{*}$ & 4.17 (3. & $6-5.50)^{\star}$ & $1.04(0$ & (9-1.36) \\
\hline Model 2 & $2.44(1.9$ & $6-3.04)^{*}$ & 2.38 & $2-3.09)^{*}$ & 3.43 & $7-4.95)^{*}$ & 3.85 & $8-5.17)^{*}$ & $1.53(1.1$ & 1-2.06)† \\
\hline Model 3 & 1.80 & $0-2.31)^{\star}$ & $1.32(0$ & 7-1.81) & 2.22 & $3-3.44)^{*}$ & 2.97 (2. & $1-4.19)^{\star}$ & $1.19(0$. & (6-1.66) \\
\hline $\begin{array}{l}\text { Note: } A U D=\text { alcohol } \\
\text { PTSD }=\text { posttraumat } \\
\text { Model } 1=\text { unadjustec } \\
\text { adjusted for age, sex } \\
\text { prevalence rate of the } \\
\text { those without the phy } \\
\text { weighted using Statis } \\
{ }^{*} p<0.001 \text {. } \\
\dagger p<0.01 \text {. } \\
\ddagger p<0.05 \text {. }\end{array}$ & $\begin{array}{l}\text { use disorder, } \mathrm{Cl} \\
\text { stress disorder } \\
\text { odds ratio; Mod } \\
\text { marital status, } \\
\text { se who have the } \\
\text { ical condition. N } \\
\text { ics Canada pop }\end{array}$ & $\begin{array}{l}=\text { confidence } \\
\text { el } 2 \text { = odds re } \\
\text { ank, Canadia } \\
\text { mental disor } \\
\text { husculoskelet } \\
\text { ulation weigh }\end{array}$ & $\begin{array}{l}\text { terval, GAD } \\
\text { o adjusted for } \\
\text { Forces type, } \\
\text { of interest a } \\
\text { problems = fi } \\
\% \text { computed }\end{array}$ & $\begin{array}{l}\text { generalized } \\
\text { ge, sex, marit } \\
\text { lucation, incor } \\
\text { hong each phy } \\
\text { omyalgia and } \\
\text { sing weightec }\end{array}$ & $\begin{array}{l}\text { xiety disorder } \\
\text { status, rank, } \\
\text {, ethnicity, all } \\
\text { ical condition; } \\
\text { husculoskelet } \\
\text { ounts rounde }\end{array}$ & $\begin{array}{l}\text { MDE = major } \\
\text { anadian Forc } \\
\text { ther mental } \\
\text { No = prevalen } \\
\text { problems; } n= \\
\text { to base } 20 \text { as }\end{array}$ & $\begin{array}{l}\text { depressive epis } \\
\text { sorders exclud } \\
\text { e of those who } \\
\text { unweighted } n \text {. } \\
\text { per Statistics }\end{array}$ & $\begin{array}{l}\text { ode, } \mathrm{PAD}=\mathrm{p} \\
\text { on, income, et } \\
\text { gg the mental } \\
\text { have the men } \\
\% \text { and } 95 \% \mathrm{C} \\
\text { anada data re }\end{array}$ & $\begin{array}{l}\text { ic disorder, } \\
\text { nicity; Model } 3 \\
\text { isorder of inter } \\
\text { I disorder of in } \\
\text { vere bootstrap } \\
\text { ease rules. }\end{array}$ & $\begin{array}{l}=\text { odds ratio } \\
\text { st; Yes = } \\
\text { erest among } \\
\text { ed and }\end{array}$ \\
\hline
\end{tabular}


Table 3: Proportions of endorsed chronic pain severity indicators among those with a pain condition with and without the mental disorder of interest

$$
\%(95 \% \mathrm{Cl})
$$

Chronic pain severity

Physical condition

No pain/mild

Moderate/severe

Chronic pain activity limitation

Other musculoskeletal problems/fibromyalgia

No major depressive

episode

Yes major depressive

episode

No panic disorder

Yes panic disorder

No posttraumatic stress

disorder

Yes posttraumatic stress

disorder

\section{Arthritis}

No panic disorder

Yes panic disorder

No posttraumatic stress

disorder

Yes posttraumatic stress

disorder

\section{Back problems}

\section{No major depressive}

episode

Yes major depressive

episode

No generalized anxiety

disorder

Yes generalized anxiety

disorder

No panic disorder

Yes panic disorder

No posttraumatic stress

disorder

Yes posttraumatic stress

disorder

Migraine

No major depressive

episode

Yes major depressive

episode

No posttraumatic stress

disorder

Yes posttraumatic stress

disorder
45.2 (34.8-56.8)

$n=587$
$30.9(28.8-33.3)$
$n=148$
$58.8(52.6-65.6)$
$n=641$
$32.3(30.3-34.6)$
$n=73$
$63.6(54.2-73.0)$
$n=594$
$31.0(28.9-33.3)$
$n=125$
$65.5(57.5-73.0)$

$n=1293$

$69.1(66.8-71.2)$

$n=98$

40.3 (34.4-47.4)

$n=1323$

67.7 (65.5-69.8)

$n=40$

36.4 (27.1-45.8)

$n=1313$

$69.0(66.8-71.1)$

$$
n=60
$$

34.5 (27.1-42.5)

$65.5(57.5-73.0)$

$48.3(4 \overline{4} .8-51.8)$

51.7 (48.2-55.2)

18.5 (11.1-31.8)

$$
n=419
$$

53.6 (49.8-57.0)

$n=15$

17.9 (10.7-29.6)

81.5 (68.2-88.9)

$n=357$

46.7 (43.0-50.2)

$n=72$

$82.1(70.5-89.3)$

$$
n=878
$$

61.3 (58.6-64.0)

$$
n=72
$$

$34.3(27.8-41.5)$

$n=891$

60.4 (58.6-64.0)

$$
n=52
$$

33.8 (26.0-42.4)

$n=892$

59.8 (57.1-62.4)

$n=36$

35.2 (25.6-45.7)

$$
n=880
$$

61.3 (58.7-64.0)

$n=52$

$29.3(23.1-37.5)$

$$
n=351
$$

$69.0(64.4-72.8)$

$$
n=52
$$

$51.0(41.2-60.3)$

$n=361$

69.2 (65.2-73.3)

$$
n=37
$$

$$
n=549
$$

38.7 (36.0-41.4)

$n=135$

65.6 (58.5-72.2)

$n=582$

$39.8(37.1-42.4)$

$$
n=97
$$

$66.2(57.6-74.0)$

$$
n=594
$$

40.2 (37.6-42.9)

$$
n=70
$$

64.8 (54.3-74.4)

$$
n=548
$$

38.7 (36.0-41.4)

$n=122$

69.5 (62.5-76.9)

$$
n=154
$$

31.4 (27.2-35.6)

$$
n=55
$$

49.0 (39.7-58.8)

$n=156$

30.8 (26.7-34.8)

$$
n=49
$$

$54.8(43.2-65.2)$

Note: $n$ = unweighted; percentages and $95 \%$ Cls were bootstrapped and weighted using Statistics Canada population weights. Percentages were computed using weighted counts rounded to base 20 as per Statistics Canada data release rules. $\mathrm{Cl}=$ confidence interval.

*Denotes a significant interaction term. Only relationships significant in AOR2 in Table 2 included. No other interaction terms were significant. 
the association between pain conditions and mental disorders varied depending on the disorder, with robust findings for PTSD. Among respondents with a pain condition, trends emerged that suggest higher estimates of more severe pain indicators - in terms of both pain severity and activity limitation - in respondents with a comorbid mental disorder compared with those without.

As seen among members released from the CAF, ${ }^{29}$ chronic pain is common among active members of the CAF (25.5\%), with most respondents reporting their pain as moderate to severe. Indeed, $75 \%$ of members with chronic pain reported some impact on functioning. High rates of pain conditions were also found and may be explained by the physically intensive work demands of the participants. Military work is often unpredictable and demanding, ${ }^{30}$ and deployed soldiers endure high rates of non-battle injury ${ }^{31}$ and poly-traumatic injuries. ${ }^{32}$ Pain conditions could be sequelae of past injuries, considering that injury-induced arthritis ${ }^{33}$ and injury-related disc degeneration ${ }^{34}$ do occur. Migraines and other back problems could also be related to injury. ${ }^{35,36}$

We identified 2 unique comorbidity trends: nonsignificant relations between physical conditions and alcohol use disorder and robust findings related to PTSD. Alcohol use is associated with chronic physiologic disease ${ }^{37}$ however, the nature of the study population could explain our nonsignificant findings. Alcohol use disorder — a functionally impairing disorder may not manifest in a population who are capable of working as active militants, suggesting lower drinking impairment. This explanation is likely, given the prevalence of alcohol use disorder is lower in the regular force population compared with the general population. ${ }^{38}$ This may be particularly true for personnel with pain conditions, where the combination may result in an inability to work.

Unlike alcohol use disorder, PTSD had strong associations with all assessed pain conditions, paralleling trends seen in the general population. ${ }^{39}$ PTSD may be associated with a pain condition through its symptom profile or through a secondary mechanism such as maladaptive behaviour. For example, sleep disturbance is commonly seen in PTSD,${ }^{40}$ is associated with physical illness ${ }^{41-45}$ and is often seen in veterans, ${ }^{46}$ making poor sleep a possible propagating factor. Escape-avoidance behaviours (drinking, smoking, etc.) are used to cope after trauma, ${ }^{47,48}$ and are associated with several health conditions. ${ }^{49-53}$ Deployment may prompt these behaviours, ${ }^{54}$ corroborated by increased smoking incidences in deployed compared with nondeployed personnel. ${ }^{55}$ Additional possible mechanisms may include physiologic indicators (e.g., increases in proinflammatory cytokines after exposure to stress) or genetic factors. ${ }^{56}$ Back problems remained significant with most mental disorders in the fully adjusted model, possibly owing to the heterogeneity of the group or the psychosomatic features indicated in back pain. ${ }^{57}$

Among significantly related mental and physical health conditions, cross-tabulations showed increased pain severity indicators among respondents with comorbid physical and mental health conditions compared with those with a physical condition alone. This trend was again particularly

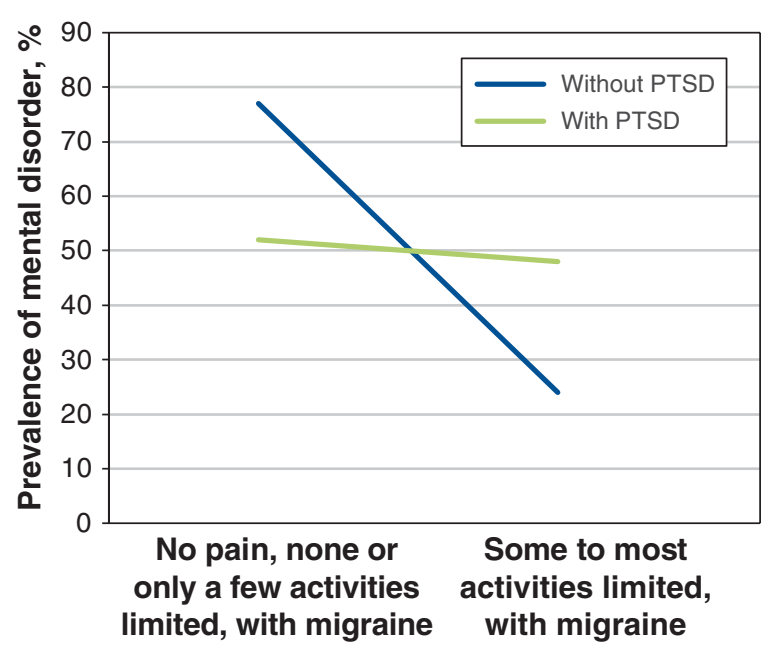

Figure 1: Formal interaction analysis between migraine and activity limitation in posttraumatic stress disorder (PTSD).

robust for PTSD. Although PTSD emerged as a robust indicator, the importance of investigating individual mental disorders among this population is supported; significant associations between physical conditions and several mental disorders remained present in the fully adjusted model, which accounted for sociodemographic factors and mental disorders (excluding the disorder of interest). Moreover, non-PTSD psychiatric disorders have been shown to be similarly disabling compared with PTSD in military populations..$^{58,59}$

\section{Limitations}

A cross-sectional survey design was used, therefore causal inferences cannot be made. In addition, reliance on selfreported pain conditions may result in biased estimates, particularly for physical conditions that are inadequately defined (e.g., back problems, musculoskeletal problems), thereby possibly inflating estimates of these pain conditions. However, some research has shown a high concordance between self-reported physical conditions and physiciandiagnosed conditions. ${ }^{60}$

Missing data could result in response bias, which should be considered when interpreting our results. Finally, focusing on the the survey sample narrows generalizability of our findings to all regular force members of the CAF. Furthermore, with most of the participants in our sample being male, our findings may be less generalizable to female military personnel.

\section{Conclusion}

A substantial number of regular force personnel have chronic physical health conditions often associated with chronic pain. Furthermore, there is high comorbidity between pain conditions and mental disorders, particularly 
PTSD. An emphasis on screening for mental disorders (particularly in the context of pain conditions) and prompt management of pain conditions in the primary care setting in the CAF is implied. Longitudinal research examining the development of comorbid mental and pain conditions within this population should be a priority. Moreover, these health conditions continue to persist after members are released from service. ${ }^{18}$ Thus, greater understanding of these comorbidities and their impact on people's abilities to adapt to military and civilian life is needed.

\section{References}

1. VanDenKerkhof EG, VanTil L, Thompson JM, et al. Pain in Canadian veterans: analysis of data from the Survey on Transition to Civilian Life. Pain Res Manag 2015;20:89-95.

2. Thompson JM, Van'Til LD, Zamorski MA, et al. Mental health of Canadian Armed Forces Veterans: review of population studies. 7 Mil Veteran Fam Heal 2016;2:70-86. doi10.3138/jmvfh.3258.

3. Reitsma ML, Tranmer JE, Buchanan DM, et al. The prevalence of chronic pain and pain-related interference in the Canadian population from 1994 to 2008. Chronic Dis Inj Can 2011;31:157-64

4. Thompson J, MacLean MB, Val Til L, et al. Survey on transition to civilian life: report on regular force veterans. Ottawa: Research Directorate, Veterans Affairs Canada, Charlottetown, and Director General Military Personnel Research and Analysis, Department of National Defence; 2011.

5. Statistics Canada Survey results in tabular form. Ottawa: National Defence and the Canadian Armed Forces; 2002. Available: http://www.forces.gc.ca/en/ about-reports-pubs-health/cchs-cf-supplement-2002-tables.page (accessed 2016 June 24).

6. Atlantis E, Shi Z, Penninx BJWH, et al. Chronic medical conditions mediate the association between depression and cardiovascular disease mortality. Soc Psychiatry Psychiatr Epidemiol 2012;47:615-25.

7. Stein MB, Cox BJ, Afifi TO, et al. Does co-morbid depressive illness magnify the impact of chronic physical illness? A population-based perspective. Psychol Med 2006;36:587-96

8. Gunn JM, Ayton DR, Densley K, et al. The association between chronic illness, multimorbidity and depressive symptoms in an Australian primary care cohort. Soc Psychiatry Psychiatr Epidemiol 2012;47:175-84.

9. Gabilondo A, Vilagut G, Pinto-Meza A, et al. Comorbidity of major depressive episode and chronic physical conditions in Spain, a country with low prevalence of depression. Gen Hosp Psychiatry 2012;34:510-7.

10. Fiest KM, Currie SR, Williams JVA, et al. Chronic conditions and major depression in community-dwelling older adults. F Affect Disord 2011;131: $172-8$.

11. El-Gabalawy R, Mackenzie CS, Shooshtari S, et al. Comorbid physical health conditions and anxiety disorders: a population-based exploration of prevalence and health outcomes among older adults. Gen Hosp Psychiatry 2011;33: 556-64.

12. Sareen J, Jacobi F, Cox BJ, et al. Disability and poor quality of life associated with comorbid anxiety disorders and physical conditions. Arch Intern Med 2006; 166:2109-16.

13. Sareen J, Cox BJ, Clara I, et al. The relationship between anxiety disorders and physical disorders in the U.S. National Comorbidity Survey. Depress Anxiety 2005;21:193-202.

14. Pacella ML, Hruska B, Delahanty DL. The physical health consequences of PTSD and PTSD symptoms: a meta-analytic review. 7 Anxiety Disord 2013; 27:33-46.

15. Fetzner MG, Mcmillan KA, Asmundson GJG. Similarities in specific physical health disorder prevalence among formerly deployed Canadian Forces veterans with full and subsyndromal PTSD. Depress Anxiety 2012;29:958-65.

16. Demyttenaere K, Bruffaerts R, Lee S, et al. Mental disorders among persons with chronic back or neck pain: Results from the world mental health surveys. Pain 2007;129:332-42.

17. Buist-Bouwman MA, De Graaf R, Vollebergh WAM, et al. Comorbidity of physical and mental disorders and the effect on work-loss days. Acta Psychiatr Scand 2005;111:436-43.

18. Thompson JM, Pranger T, Sweet J, et al. Disability correlates in Canadian Armed Forces Regular Force Veterans. Disabil Rehabil 2015;37:884-91.

19. Scott KM, Von Korff M, Alonso J, et al. Mental - physical co-morbidity and its relationship with disability: results from the World Mental Health Surveys. Psychol Med 2009;39:33-43.

20. El-Gabalawy R, Thompson JM, Sweet J, et al. Comorbidity and functional correlates of anxiety and physical conditions in Canadian Veterans. 7 Mil Veteran Fam Heal 2015;1:37-46.

21. O'Toole BI, Catts SV. Trauma, PTSD, and physical health: an epidemiological study of Australian Vietnam veterans. 7 Psychosom Res 2008;64:33-40.
22. Canadian Forces Mental Health Survey. Ottawa: Statistics Canada; 2014. Available: http://www23.statcan.gc.ca/imdb/p2SV.pl? Function=getSurvey \&SDDS=5084 (accessed 2016 June 20).

23. Kessler RC, Üstün TB. The World Mental Health (WMH) Survey Initiative Version of the World Health Organization (WHO) Composite International Diagnostic Interview (CIDI). Int F Methods Psychiatr Res 2004;13:93-121.

24. American Psychiatric Association. Diagnostic and statistical manual of mental disorders. Fifth edition. Arlington (VA): American Psychiatric Association Publishing; 2013.

25. Haro JM, Arbabzadeh-bouchez S, Brugha TS, et al. Concordance of the Composite International with standardized clinical assessments in the WHO World Mental Health Surveys. Int 7 Methods Psychiatr Res 2006;15:167-80.

26. Afifi TO, Taillieu T, Zamorski MA, et al. Association of child abuse exposure with suicidal ideation, suicide plans, and suicide attempts in military personnel and the general population in Canada. FAMA Psychiatry 2016;73:229-38.

27. Zamorski MA, Bennett RE, Boulos D, et al. The 2013 Canadian Forces Mental Health Survey: background and methods. Can 7 Psychiatry 2016;61(Suppl 1): 10S-25S.

28. Software SS. StataCorp. 2015.

29. VanDenKerkhof EG, VanTil L, Thompson JM, et al. Pain in Canadian veterans: analysis of data from the Survey on Transition to Civilian Life. Pain Res Manag 2015;20:89-95.

30. Boulos D, Zamorski MA. Military occupational outcomes in Canadian Armed Forces personnel with and without deployment-related mental disorders. Can 7 Psychiatry 2016;61:348-57.

31. Patel AA, Hauret KG, Taylor BJ, et al. Non-battle injuries among U.S. Army soldiers deployed to Afghanistan. 7 Safety Res 2017;60:29-34.

32. Geiling J, Rosen JM, Edwards RD. Medical costs of war in 2035: long-term care challenges for veterans of Iraq and Afghanistan. Mil Med 2012;177:1235-44.

33. Brown TD, Johnston RC, Saltzman CL, et al. Posttraumatic osteoarthritis: a first estimate of incidence, prevalence, and burden of disease. 7 Orthop Trauma 2006;20:739-44.

34. Adams MA. Biomechanics of back pain. Acupunct Med 2004;22:178-88.

35. Knapik JJ, Reynolds K, Harman E. Soldier load carriage: historical, physiological, biomechanical, and medical aspects. Mil Med 2004;169:45-56.

36. Patil VK, Andre JRS, Crisan E, et al. Prevalence and treatment of headaches in veterans with mild traumatic brain injury. Headache 2011;51:1112-21.

37. Rehm J, Mathers C, Popova S, et al. Global burden of disease and injury and economic cost attributable to alcohol use and alcohol-use disorders. Lancet 2009;373:2223-33.

38. Rusu C, Zamorski MA, Boulos D, et al. Prevalence comparison of past-year mental disorders and suicidal behaviours in the Canadian Armed Forces and the Canadian General population. Can 7 Psychiatry 2016;61(Suppl 1): 46S-55S.

39. Sareen J, Cox BJ, Stein MB, et al. Physical and mental comorbidity, disability, and suicidal behavior associated with posttraumatic stress disorder in a large community sample. Psychosom Med 2007;69:242-8.

40. Desk reference to the diagnostic criteria from DSM-5. Arlington (VA): American Psychiatric Association; 2013.

41. Gangwisch JE, Heymsfield SB, Boden-albala B, et al. Short sleep duration as a risk factor for hypertension analyses of the First National Health and Nutrition Examination Survey. Hypertension 2006;47:833-9.

42. Schwartz SW, Cornoni-huntley J, Cole SR, et al. Are sleep complaints an independent risk factor for myocardial infarction? Ann Epidemiol 1998;8: 384-92.

43. Ayas NT, White DP, Al-Delaimy WK, et al. A prospective study of selfreported sleep duration and incident diabetes in women. Diabetes Care 2003;26: 380-4.

44. Ayas NT, White DP, Manson JE, et al. A prospective study of sleep duration and coronary heart disease in women. Arch Intern Med 2003;163:205-9.

45. Zee PC, Turek F. Sleep and health. Arch Intern Med 2006;166:1686-8.

46. Lewis V, Creamer M, Failla S. Is poor sleep in veterans a function of posttraumatic stress disorder? Mil Med 2009;174:948-51.

47. Chang C-M, Lee L-C, Connor K, et al. Posttraumatic distress and coping strategies among rescue workers after an earthquake. 7 Nerv Ment Dis 2003; 191:391-8.

48. Olff $M$, Langeland W, Olff $M$, et al. The psychobiology of PTSD: coping with trauma. Psychoneuroendocrinology 2005;30:974-82.

49. Bartecchi CE, MacKenzie TD, Schrier RW. The human costs of tobacco use. N Engl 7 Med 1994;330:907-12.

50. Rehm J, Monteiro M. Alcohol consumption and burden of disease in the Americas: implications for alcohol policy. Rev Panam Salud Publica 2005;18: 241-8.

51. Russell M, Rasmussen B, Fenger K, et al. Migraine without aura and migraine with aura are distinct clinical entities: a study of four hundred and eighty-four male and female migraineurs from the general population. Cephalalgia 1996;16:239-45

52. Panconesi A. Alcohol and migraine trigger factor, consumption, mechanisms. A review. 7 Headache Pain 2008;9:19-27.

53. Yunus MB, Arslan S, Aldag JC, et al. Relationship between fibromyalgia features and smoking. Scand 7 Rheumatol 2002;31:301-5. 
54. Sudom K, Zamorski M, Garber B. Stigma and barriers to mental health care in deployed Canadian Forces Personnel. Mil Psychol 2012;24:414-31.

55. Smith B, Ryan MAK, Wingard DL, et al. Cigarette smoking and military deployment. Am f Prev Med 2008;35:539-46.

56. Stein MB, Chen C, Ursano RJ, et al. Genome-wide association studies of posttraumatic stress disorder in 2 cohorts of US Army soldiers. FAMA Psychiatry 2016;73:695-704.

57. Chaturvedi SK, Parameshwaran S. Psychosomatic medicine. In: International encyclopedia of social \& behavioral sciences. Vol. 19. 2nd ed. Elsevier; 2015:484-90.

58. Piccirillo AL, Packnett ER, Boivin MR, et al. Epidemiology of psychiatric disability without posttraumatic stress disorder among U.S. Army and Marine Corps personnel evaluated for disability discharge. 7 Psychiatr Res 2015;71:56-62.

59. Muschalla B, Rau H, Willmund GD, et al. Work disability in soldiers with posttraumatic stress disorder, posttraumatic embitterment disorder, and notevent-related common mental disorders. Psychol Trauma 2018;10:30-5.

60. Baumeister H, Kriston L, Bengel J, et al. High agreement of self-report and physician-diagnosed somatic conditions yields limited bias in examining mental-physical comorbidity. 7 Clin Epidemiol 2010;63:558-65.

Affiliations: Max Rady College of Medicine, University of Manitoba (Vun); Departments of Community Health Sciences (Turner, Afifi), Psychiatry (Sareen, Afifi, Mota, El-Gabalawy), Clinical Health Psychology (Mota, El-Gabalawy), Anesthesiology, Perioperative and Pain Medicine (El-Gabalawy), Max Rady College of Medicine, University of Manitoba, Winnipeg, Man.
Contributors: Everett Vun contributed to the conception, design, acquisition of data, analysis, drafting and revising the article; Sarah Turner contributed to the acquisition of data, analysis, interpretation, drafting and revision of the article; Jitender Sareen contributed to the conception, design, acquisition of data, interpretation of data and revision of the article; Natalie Mota contributed to the design, interpretation and revision of the article; Tracie Afifi contributed to the design, interpretation and revision of the article; Renée El-Gabalawy contributed to the conception, design, acquisition of data, analysis, interpretation of data, revisions of the article and gave final approval for the version to be submitted. All of the authors approved the final version of the article and agreed to act as guarantors of the results.

Acknowledgements: The authors thank Jordana Sommer and Kayla Kilborn for their contributions.

Funding: This study was supported by the Mary E. Hedley Bequest, a research contract from the Government of Canada (Sareen), University of Manitoba Start-Up funds and internal funds from the Department of Anesthesiology, Perioperative and Pain Medicine, and the Canadian Institutes of Health Research Chronic Pain Network (El-Gabalawy).

Supplemental information: For reviewer comments and the original submission of this manuscript, please see www.cmajopen.ca/content/6/4/ E528/suppl/DC1. 